\title{
Analysis of China's Financial Development and Its Impact on Energy Efficiency
}

\author{
Yi-Wei Zhou', Li-Chen $\mathrm{Chou}^{2, *}$ \\ ${ }^{1}$ Department of Finance, Wenzhou Business College, China \\ ${ }^{2}$ Department of Economics, Wenzhou Business College, China
}

\begin{abstract}
This paper combs the literature related to financial development and energy research. Reviewing the relevant literature, we find that few studies in China have paid attention to the changes of efficiency and energy productivity in the financial industry as well as their correlation. The interlinkage between green finance and energy efficiency is still a topic that has been less discussed. In addition, considering the untouched issues in these studies, this paper proposes the application of Metafrontier performance theory.
\end{abstract}

\section{Introduction}

Green Finance, also known as environmental finance or sustainable finance. The financial industry and the environmental protection community use their respective systems, languages and methods to define the concept of green finance. Although scholars have made different views on the concept of green finance, its core still surrounds environmental protection and sustainable development. In summary, Green Finance aims to solve global environmental pollution and climate change through the combination of optimal financial instruments and financial products to achieve sustainable economic, social and environmental development [4].

Nowadays, environmental protection issues are becoming increasingly important in all countries around the world. Environmental issues have risen to global economic and political issues, which are related to sustainable development of human society in the future. We have reached consensus to strengthen environmental protection and realize sustainable development of economic society. In order to alleviate environmental problems and adapt to climate change, some international organizations, government departments, and academic institutions have explored various paths to achieve sustainable development strategy. In the context of environmental protection and sustainable development, the concept of green finance was first introduced in 1991. So far, experts and scholars in various fields at home and abroad have made some achievements in researching green finance but haven't formed a perfect system yet.

Compared with traditional finance, green finance pays more attention to considering environmental protection in an economic activity, instead of pursuing economic benefits as traditional finance. Through the development of green finance, we emphasize balance

\footnotetext{
* Corresponding author: edcv2581013@gmail.com
} 
between financial activities, environmental protection and ecological harmonious development. Ultimately sustainable development of economic society can be achieved through balancing environmental protection and economic benefits.

Green finance and traditional finance still share a similarity, that is, both of them need the strong support of the government. Green finance can develop rapidly and accepted by more entrepreneurs through encouraging government policies. There will be no long-term sustainable development if only economic interests are considered in a reckless manner.

As the country with the most rapid economic growth in recent years, China will certainly not lag behind in this field. Green finance development in China can be traced to the period of reform and opening up in the 1980s. Especially in recent years, green finance has made achievements in legal policy environment, scale volume, and market institution construction etc. Green financial practices in China, represented by green credit, have already been advanced in the world.

Firstly, under the impetus of government, China's green financial regulation system has been established step by step. The Chinese government has focused on environmental protection from the beginning of reform and opening up, and the relevant departments have issued some documents related to green finance. At the beginning of the 21st century, environmental protection mode of the Chinese government began to change from administrative means to the comprehensive use of legal, economic, financial, and technical means to solve environmental problems. During the Eleventh Five-year Plan period, China initially decided to establish a green financial policy system. The Twelfth Five-year Plan includes green finance including environmental economic policy unified planning for the first time. The 2013 Third Plenary Session of the 18th Central Committee proposes to accelerate the construction of ecological civilization system, which created a higher level authority and stronger environmental economic policy space for the development of China's green finance. Currently, China's green financial policy system mainly includes two categories: policies directly related to green finance and supporting policies related to finance, taxation, price and infrastructure construction. Generally speaking, the basic framework of China's green financial policy system has been preliminarily formed, which has played a key role in the initiation and development of China's green financial market. This paper has two research goals: one is to comb literature related to financial development and energy research. Another is to use Metafrontier performance theory to analyse the less researched issues.

\section{Literature}

The literature collected for this study explores economic development and technical efficiency in different provinces of mainland China. Some studies have focused on the impact of the uneven distribution of foreign direct investment on provincial development (Cheng, Chiu, and Lin 2006). Hsu (2006) applied the Data Envelopment Analysis (DEA) model and the Stochastic Frontier Analysis (SFA) model to analyze the production output of Zhejiang province in different years. The empirical results show that export-oriented economy, financial development, industrial integration, urbanization, and technological investment have a significantly positive impact on technical efficiency of regional economic development. Zhang and $\mathrm{Xu}$ (2008) used the statistical data for Zhejiang province from 1952 to 2005 and estimated the technical efficiency and production frontier by using the Cobb-Douglas SFA production function. Empirical results indicate that the loss of production and technical efficiency in Zhejiang and coastal regions is low; however, due to effective economic reform and institutional innovation, the level of technical efficiency in Zhejiang has improved. 
The above literature suggests that previous studies tended to focus on similar technical priorities in their assessments. In reality, however, companies in different regions operate differently. To be more specific, they have different management styles, locations, labor skills, and inputs, which may lead to different production behaviours. The same view was taken on the heterogeneity of production technology in the provinces of China and studies the energy efficiency, such as Wang et al. (2013), Lin and Du (2013), Hang et al. (2015). It indicates that the heterogeneity of production technology in provinces will lead to the deviation of energy efficiency evaluation.

In the discussions in the field of energy research, Hang et al. (2015) discussed the energy inefficiency with poor output and technological heterogeneity, and found that the average energy inefficiency of Chinese cities was about 0.305 . Wang et al. (2016) proposed a comprehensive index construction method considering heterogeneity, and take 2005-2010 as the research cycle. It was concluded that the central region of China has the best sustainable energy development level in 2010; Wang et al. (2016) investigated the carbon dioxide emissions and technology gaps in 54 countries. The empirical results of the study concluded that the performance of upper middle income countries is worse than high income countries. Management inefficiency and technology gaps has a negative impact on carbon dioxide emission performance, while inefficient management has played a leading role.

Combing the domestic and foreign studies, we can find that the following topics of current research on financial performance and energy efficiency difference still needs to be filled by follow-up research.

(1) Few studies in China have noticed the changes in the efficiency and energy productivity of the financial industry and their correlation. China is in the stage of economic transformation, and the development of financial industry is becoming increasingly important. At the same time, in the growing emphasis on environmental sustainability, the interconnection between green finance and energy efficiency remain less discussed.

(2) Most of the studies fail to take into account the differences in production technology in different regions. Most of them assume that research samples and decision-making units have the same or homogeneous production technology and directly evaluate the industrial efficiency. In reality, there are differences in production patterns and economic scales in different regions and cities in China. If these differences are not taken into account, efficiency evaluation results may produce overestimation or underestimation, which in turn affects research inference.

(3) Most of the studies focus on typical cities or specific regions in China, which has not covered the whole region. Therefore, the results of the assessment can not conclude the overall macro changes.

To sum up, this paper intends to apply the common frontier model (Metafrontier) theory to discuss the industry efficiency and energy efficiency of the financial industry. Through the construction and evaluation of the theoretical model, this paper compares the distribution of financial industry performance and efficiency of different urban groups.

\section{Methodology}

The research methods are as follows:

Suppose $J=1, \ldots, \mathrm{R}$ represents a group, and each group has NJ cities. The No. i city of group $\mathrm{j}$ has a financial industry output at No.t phase. Represented by Yit (j), the group stochastic frontier production function is set as follows:

$$
Y_{i t(j)}=f\left(X_{i t(j)} ; \beta_{(j)}\right) e^{V_{i t(j)}-U_{i t(j)}}
$$


In the formula, $\mathrm{i}=1, \ldots, \mathrm{Nj}, \mathrm{t}=1, \ldots, \mathrm{T}$. Xit (j) is the factor input vector of the No.i city in the No.j group, and is the technical parameter vector of the No.j group, which must be estimated by the sample data of the individual groups. It is estimated with the Battese and Coelli (1995) Stochastic Frontier model and the maximum likelihood method is used to estimate. Vit is a random interference term, which is the same and independent normal random variable, that is, define a non-negative random variable Uit as:

$$
U_{i t}=Z_{i t} \delta+W_{i t} \geq 0
$$

It represents technical inefficiency, where Zit is a $1 \mathrm{xM}$ exogenous environment variable vector and $\mathrm{Mx} 1$ is unknown parameter vector. $\delta$ represents a non-observable random interference item with a normal distribution. Its average value is 0 , and variance is $\sigma_{w}^{2}$, which satisfies $W_{i t} \geq-Z_{i t} \delta$, which is independent of Vit. The estimated value of technical efficiency of financial industry in individual cities is: $T E_{i t}=\exp \left(-\hat{U}_{i t}\right)=\exp \left(-Z_{i t} \hat{\delta}-\hat{W}_{i t}\right)$. Suppose $\mathrm{f}(\cdot)$ is a logarithmic linear production function, formula (1) becomes:

$$
Y_{i t(j)} \equiv e^{X_{i t(j)} \beta_{(j)}+V_{i t(j)}-U_{i t(j)}}
$$

Presume that the common frontier production functions of each city are as follows:

$$
Y_{i t}^{*} \equiv f\left(X_{i t}, \beta^{*}\right)=e^{X_{i i} \beta^{*}}, i=1, \ldots, N=\sum_{j=1}^{R} N_{j}, t=1, \ldots, T
$$

And

$$
X_{i t} \beta^{*} \geq X_{i t} \beta_{(j)}
$$

The common boundary frontier function of the formula (4) essentially belongs to the deterministic parameter function, which can be regarded as the envelope curve of production function for each group. It should be greater than or equal to the optimal output level of individual groups.

If we change formula (3) into:

$$
Y_{i t(j)}=e^{-U_{i t(j)}} \times \frac{e^{X_{i t} \beta_{(j)}}}{e^{X_{i t} \beta^{*}}} \times e^{X_{i t} \beta^{*}+V_{i t(j)}}
$$

The first item on the right of the equal sign is the technical efficiency index TEit (j), for the No.j group, which is defined as:

$$
T E_{i t(j)}=\frac{Y_{i t(j)}}{e^{X_{i t} \beta_{(j)}+V_{i t(j)}}}=e^{-U_{i t(j)}}
$$

Formula (7) represents the difference between the actual financial industry output of the No.j city and the optimal output level of the group. When the technical efficiency is higher, the output value of the financial industry of the No.i city is closer to the optimal output. In formula (6), the second term to the right of the equal sign is called the technical gap ratio (TGR), which represents the ratio of the boundary output to the potential output of the common production function, with a value between 0 and 1 .

The technology gap ratio is expressed as follows: 


$$
T G R_{i t(j)}=\frac{e^{X_{i i} \beta_{(j)}}}{e^{X_{i i} \beta^{2}}}
$$

Through formula (6) and formula (8), the technical efficiency of the common boundary frontier can be decomposed as follows:

$$
T E_{i t}^{*}=T E_{i t(j)} \times T G R_{i t(j)}
$$

$T E_{i t}^{*}$ is the ratio that actual output takes in the maximum possible output level of No.i city in phase No. $t$ to, representing the frontier technical efficiency of the common boundary. The two-stage common frontier function estimation steps will be used in the empirical evaluation process of the project, which can be summarized as follows:

The first stage: using data Envelopment Analysis (DEA) (or Stochastic Frontier Model), and mathematical programming model (or maximum likelihood method) to estimate the city's Translog Production Function, cost function, and calculate financial industry production performance, and efficiency estimates of each city.

The second stage: using the method proposed by Battese et al. (2004) to estimate the parametric vectors of common boundary frontier function. To be more specific, to solve the following optimization problems with a minimized distance squared sum and minimum sum of squares of deviations.

$$
\operatorname{Min} L L \equiv \sum_{i=1}^{N} \sum_{t=1}^{T}\left(X_{i t} \beta^{*}-X_{i t} \hat{\beta}_{(j)}\right)^{2}
$$

s.t. $\quad X_{i t} \beta^{*} \geq X_{i t} \hat{\beta}_{(j)}$

The above formula indicates the gap between real input and optimal input in the economic activities of urban financial industry, and the parameter vectors is calculated by using the minimum gap value. Based on the parameter estimation obtained in the second stage, the financial efficiency of the city can be calculated considering the differences in technical nature. Coupled with the efficiency estimates obtained in the first stage, the technology gap ratios of city groups are measured with different production activities and different economic scales.

Lastly, in the course of the study, we intend to use urban energy consumption and efficiency as environmental variables of industrial production, discuss the causal correlation between them, and incorporate them into the analysis of their related influences.

\section{Conclusion}

This paper combs literature related to financial development and energy research. Furthermore, considering the untouched topics in these studies, this paper proposes the application of Metafrontier performance theory.

Reviewing the relevant literature, we find that few studies in China have paid attention to the changes in efficiency of the financial industry, the changing trend of energy productivity and their correlation, and the interconnection between green finance and energy efficiency is still topics of little discussion. Most of the studies fail to take into account the differences in production technology in different regions. Most of them assume that the production technologies of research samples and decision-making units are same or homogeneous and directly evaluate the industrial efficiency. Meanwhile, the object of the study is a typical city or a specific region in China. Their analysis has not summarized the whole region, thus the analysed results can not conclude the overall macro changes. Based 
on this, this paper constructs an application of the common boundary frontier model (Metafrontier) theory to analyze.

\section{References}

1. Cheng, C. D., Y. H. Chiu, and M. C. Lin, Mainland China Studies, 49(1), 53-74 (2006)

2. Hang, Y., Q.Wang, Z. Zhao, and Y. Wang, Economic Modelling, 49, 46-52 (2015)

3. Hsu, Q., Theory of Regional Technical Efficiency - a Study Based on the Technical Efficiency of Regional Economic Competitiveness (Beijing: China Economic Publishing Company, 2006)

4. Lin, B. Q., and K. R. Du, Energy Economics, 40, 529-536 (2013)

5. Wang, Q. W., Z.Y. Zhao, P. Zhou, and D. Q. Zhou, Economic Modelling, 35(5), 283289 (2013)

6. Wang, H., P. Zhou, and Q. Wang, Energy, 151(5), 218-228 (2016)

7. Zhang, S. F., and B. Xu, Zhejiang Social Science, 3(1), 42-46 (2008) 